\title{
Trans-Signaling Is a Dominant Mechanism for the Pathogenic Actions of Interleukin-6 in the Brain
}

\author{
Iain L. Campbell, ${ }^{1}$ Maria Erta, ${ }^{2}$ Sue Ling Lim, ${ }^{1}$ Ricardo Frausto, ${ }^{1}$ Ulrike May, ${ }^{3}$ Stefan Rose-John, ${ }^{3}$ Jürgen Scheller, ${ }^{4}$ \\ and Juan Hidalgo ${ }^{2}$ \\ ${ }^{1}$ School of Molecular Bioscience, The University of Sydney, New South Wales 2006, Australia, ${ }^{2}$ Department of Cellular Biology, Physiology and \\ Immunology, Universitat Autònoma de Barcelona, Barcelona 08193, Spain, ${ }^{3}$ Department of Biochemistry, University of Kiel, D-24098 Kiel, Germany, and \\ ${ }^{4}$ Institute of Biochemistry and Molecular Biology II, Medical Faculty, Heinrich-Heine-University, Düsseldorf, 40225 Düsseldorf, Germany
}

IL-6 is implicated in the pathogenesis of various neuroinflammatory and neurodegenerative disorders of the CNS. IL-6 signals via binding to either the membrane bound IL-6R $\alpha$ (classic signaling) or soluble (s)IL-6Ra (trans-signaling) that then form a complex with gp130 to activate the JAK/STAT signaling pathway. The importance of classic versus trans-signaling in mediating IL-6 actions in the living CNS is relatively unknown and was the focus of this investigation. Bigenic mice (termed GFAP-IL6/sgp130 mice) were generated with CNSrestricted, astrocyte-targeted production of IL-6 and coproduction of the specific inhibitor of IL-6 trans-signaling, human sgp130-Fc. Transgene-encoded IL-6 mRNA levels were similar in the brain of GFAP-IL6 and GFAP-IL6/sgp130 mice. However, GFAP-IL6/sgp130 mice had decreased $\mathrm{pY}^{705}$-STAT3 in the brain due to a reduction in the total number of $\mathrm{pY}^{705}$-STAT3-positive cells and a marked loss of $\mathrm{pY}^{705}$-STAT3 in specific cell types. Blockade of trans-signaling in the brain of the GFAP-IL6 mice significantly attenuated Serpina3n but not SOCS3 gene expression, whereas vascular changes including angiogenesis and blood- brain barrier leakage as well as gliosis were also reduced significantly. Hippocampal neurogenesis which was impaired in GFAP-IL6 mice was rescued in young GFAP-IL6 mice with cerebral sgp130 production. Finally, degenerative changes in the cerebellum characteristic of GFAP-IL6 mice were absent in GFAP-IL6/ sgp 130 mice. The findings indicate that in the CNS: (1) sgp130 is able to block IL-6 trans-signaling, (2) trans-signaling is important for IL-6 cellular communication with selective cellular and molecular targets, and (3) blocking of trans-signaling alleviates many of the detrimental effects of IL-6.

Key words: interleukin-6; neuropathology; signal transduction; trans-signaling; transgenic mouse

\section{Introduction}

The cytokine IL-6 is implicated in the pathogenesis of various pathologic states including infection, autoimmunity, neurodegeneration, and trauma (Spooren et al., 2011). Insights to the neurological impact of IL-6 have come from a transgenic model (named GFAP-IL6) with astrocyte production of IL-6 (Campbell et al., 1993). GFAP-IL6 mice exhibit a localized neuroinflammatory and neurodegenerative disorder associated with various deficits (Campbell, 1998; Campbell et al., 2010). The GFAP-IL6

Received July 3, 2013; revised Nov. 26, 2013; accepted Jan. 3, 2014.

Author contributions: I.L.C., M.E., S.R.-J., J.S., and J.H. designed research; I.L.C., M.E., S.L.L., R.F., and U.M. performed research; I.L.C., S.R.-J., and J.S. contributed unpublished reagents/analytic tools; I.L.C., M.E., S.L.L., R.F., S.R.-J., J.S., and J.H. analyzed data; I.L.C., M.E., S.L.L., R.F., S.R.-J., J.S., and J.H. wrote the paper.

This work was supported by NHMRC project Grant 632754 to I.L.C. and SAF2011-23272 (J.H.). S.R.-J. was supported by the Deutsche Forschungsgemeinschaft, Bonn, Germany (SFB654, project C5) and by the Cluster of Excellence "Inflammation at Interfaces." M.E. is a predoctoral fellow of the Universitat Autònoma de Barcelona and was supported by a travelling fellowship. We thank Laura Parker for technical assistance, and Nadia Villacampa, Berta González, and Bernardo Castellano for helpful comments. Dr. Claudia Röhl and Monika Grell at the Institute of Anatomy, University of Kiel, Germany are thanked for their generous help with the derivation of primary astrocyte cultures.

The authors declare no competing financial interests.

Correspondence should be addressed to Dr. lain L. Campbell, School of Molecular Bioscience, The University of Sydney, Sydney, 2006 NSW, Australia. E-mail: iain.campbell@sydney.edu.au.

DOI:10.1523/JNEUROSCI.2830-13.2014

Copyright $\odot 2014$ the authors $\quad 0270-6474 / 14 / 342503-11 \$ 15.00 / 0$ model not only underscores the potential for IL-6 to cause disease in the CNS but also provides a novel tool to explore the basic mechanisms that underpin the actions of IL- 6 in the brain.

Cellular communication by IL- 6 is mediated by two distinct modes termed classic and trans-signaling, respectively (Scheller et al., 2011). Classic signaling involves IL-6 binding to a specific transmembrane receptor termed IL-6R $\alpha$. A naturally occurring soluble form of the IL-6R $\alpha$ (sIL-6R), is generated by the cleavage of the ectodomain of the transmembrane IL-6R $\alpha$ or by alternative splicing of the IL-6R $\alpha$ mRNA (Lust et al., 1992; Müllberg et al., 1993, 1999; Rose-John and Heinrich, 1994) and is found in body fluids including CSF (März et al., 1997b; Michalopoulou et al., 2004). The sIL-6R binds IL-6 and this complex confers IL-6 responsiveness by cells that lack the IL-6R $\alpha$ (Mackiewicz et al., 1992; Narazaki et al., 1993). The binding of IL-6 either to the membrane-bound or the sIL-6R triggers the oligomerization of the ubiquitous transmembrane protein gp130 resulting in activation of the JAK/STAT signal transduction pathway (Heinrich et al., 2003).

The activity of IL-6/sIL-6R is counteracted by a naturally occurring soluble form of gp130 (sgp130; Jostock et al., 2001). This antagonist prevents trans-signaling by binding the IL-6/ sIL-6R complex and this property is used as a means for 


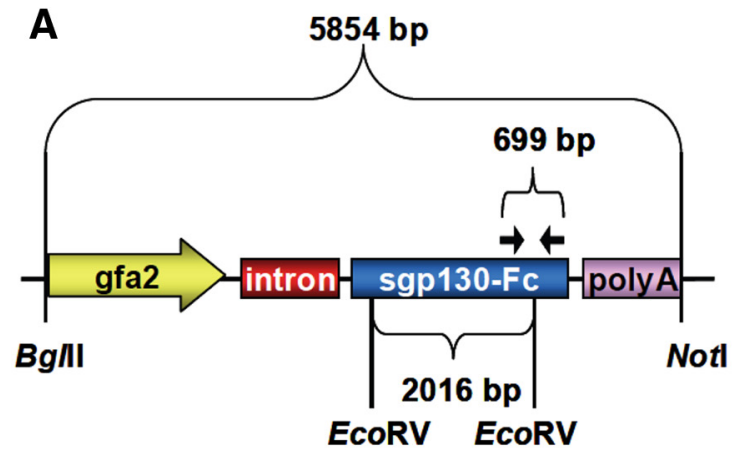

B

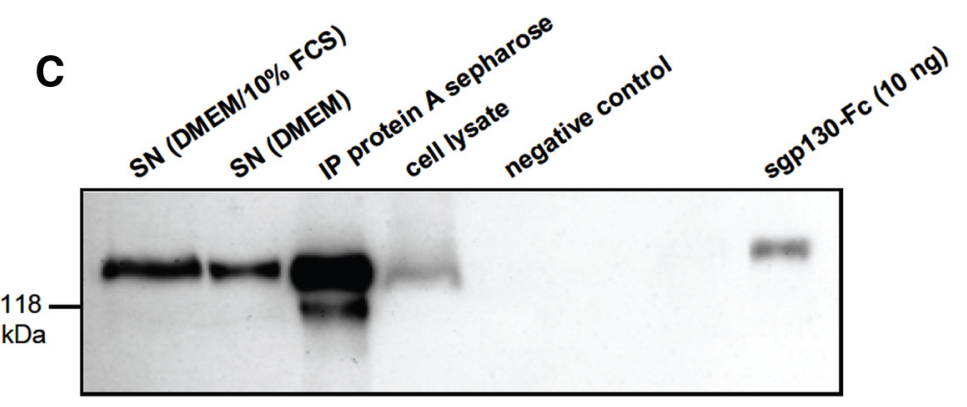

Figure 1. Generation and characterization of GFAP-sgp130 transgenic mice. $\boldsymbol{A}$, Schematic representation of the organization of the gfa2-sgp130-Fc optimized cDNA expression cassette. $\boldsymbol{B}$, Immunoblot detection of secreted sgp 130-Fc from primary astrocytes of GFAP-sgp130 transgenic mice or WT controls. Cell culture supernatants (SNs) were used directly or after coprecipitation of sgp130-Fc with protein A Sepharose. C, Immunoblot analysis after coprecipitation of hyper-IL-6 with brain-derived sgp 130-Fc from GFAP-sgp 130 transgenic mice. Brain homogenates from the three independent transgenic mouse lines 15, 18, and 19 or from WT mice were incubated with hyper-IL-6 and coprecipitated with protein A Sepharose. Coprecipitated hyper-IL-6 was detected with an IL-6R monoclonal (clone 14-18), whereas sgp130-Fc was detected with the gp130 antibody B-P4. Recombinant sgp 130-Fc (10 ng) was included as positive control.

distinguishing trans-signaling from classic signaling. In transgenic mice that overproduce sgp130 in the periphery, transsignaling but not classic IL-6 signaling is markedly ablated (Rabe et al., 2008).

Although, gp130 is expressed by nearly all cells, including those of the CNS, the surface expression of the IL-6R is more restricted (Rose-John et al., 2006). It has been shown that neurons and astrocytes respond well to IL-6/sIL-6R but not to IL-6 alone suggesting that trans-signaling is crucial for mediating the effects of IL-6 on these cells (März et al., 1997a, 1999; Van Wagoner et al., 1999). In contrast, microglia respond well to IL-6 alone via classic signaling (Lin and Levison, 2009). Recently, it was shown that intracerebroventricular injection of sgp 130 accelerated the recovery of mice from LPS-induced endotoxemia and reduced the hyperactive response of microglia to LPS in aged mice highlighting a role for IL-6 trans-signaling in these processes (Burton et al., 2011, 2013). However, much remains unknown about the role of trans-signaling in mediating the pathogenic actions of IL- 6 in the CNS. Therefore, in the current study we addressed this issue by using a newly developed GFAPsgp130 mouse model that was intercrossed with GFAP-IL6 mice to generate bigenic mice that coproduced IL- 6 and the transsignaling inhibitor, sgp130, in the brain.

\section{Materials and Methods}

Animals. GFAP-IL6 transgenic mice were generated and characterized as described previously (Campbell et al., 1993). To generate GFAP-sgp130 transgenic mice, the codon-optimized cDNA coding for human sgp130Fc (Rabe et al., 2008) was placed under the control of the minimal $2.2 \mathrm{~kb}$ GFAP promoter in the plasmid pCR-Script. The sgp130Fc is a dimeric fusion protein of the extracellular portion of gp130 and the $\mathrm{Fc}$ portion of IgG1 and blocks trans-signaling of human and murine IL-6/ sIL-6R complexes 10-100 times more efficiently than sgp130 (Jostock et al., 2001). The second intron and the polyA-sequence of the rabbit $\beta$-globin gene were placed $5^{\prime}$ and $3^{\prime}$ of the sgp $130 \mathrm{Fc}$ coding sequence, respectively. The BglII-NotI fragment of the pCR-Script-GFAPsgp $130 \mathrm{Fc}$ plasmid containing the entire expression cassette for sgp $130 \mathrm{Fc}$ (Fig. 1A) was gel purified and microinjected into the pronuclei of fertilized eggs of $\mathrm{B} 6 \mathrm{D} 2 / \mathrm{F} 1$ mice. The hybrid strain $\mathrm{B} 6 \mathrm{D} 2 / \mathrm{F} 1$ was created by a cross of a C57BL/6J (B6) female and a DBA/2 (D2) male mouse. A transgenic mouse line was established from the founder animal that exhibited the highest expression of sgp130Fc in the brain and backcrossed eight times to C57BL/6 background. Production of the GFAP-sgp130 transgenic mice was performed in accordance with the guidelines for Animal Care (Acceptance No. 35-9185.81/G-101/05). GFAP-IL6/sgp130 bigenic mice heterozygous for each transgene, GFAP-IL6 and GFAP-sgp130 single transgenic, and WT mice were derived by interbreeding of the GFAPIL6 and GFAP-sgp130 parental lines. The genotype of all mice was verified by PCR analysis of tail DNA. All mice used in this study were fed ad libitum and were maintained under specific pathogen-free conditions. Approval for the use of the mice in this study was obtained from the University of Sydney Animal Care and Ethics Committee.

BrdU administration. For experiments to analyze cellular proliferation in the CNS, mice were injected with bromodeoxyuridine (BrdU; 100 $\mathrm{mg} / \mathrm{Kg}$, i.p.; Sigma-Aldrich). To this end, 1.5- and 3-month-old mice from all genotypes $(n=3-4)$ were given six injections (every $2 \mathrm{~h}$ over a $12 \mathrm{~h}$ period) of $\mathrm{BrdU}$ in $0.9 \%$ saline solution at $\mathrm{pH} 7.0$ and were killed $6 \mathrm{~d}$ later.

Astrocyte culture. Primary astrocytes were isolated from 2-d-old mice as described by (Röhl and Sievers, 2005). For experiments, astrocytes were seeded in 6-well plates in DMEM medium complemented with or without $10 \%$ heat-inactivated FCS at a cell density of $30,000 \mathrm{cells} / \mathrm{cm}^{2}$ in $75 \mathrm{~cm}^{2}$ flasks and cultured for 1 week before use.

Total protein lysates, immunoprecipitation, and immunoblot. The sgp130-Fc protein in astrocytes, the conditioned supernatant of astrocyte cultures or in brain lysates from GFAP-sg130 transgenic mice was analyzed by immunoblotting. Primary astrocytes were harvested in ice-cold PBS, centrifuged at $16,000 \times g$ for $30 \mathrm{~s}$ and lysed in SDS loading buffer and subjected to SDS-PAGE and Western blotting. Supernatant $(500 \mu \mathrm{l})$ from astrocyte culture was incubated with $50 \mu \mathrm{l}$ protein A Sepharose 


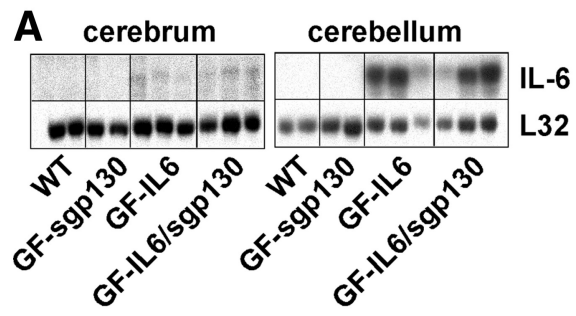

B
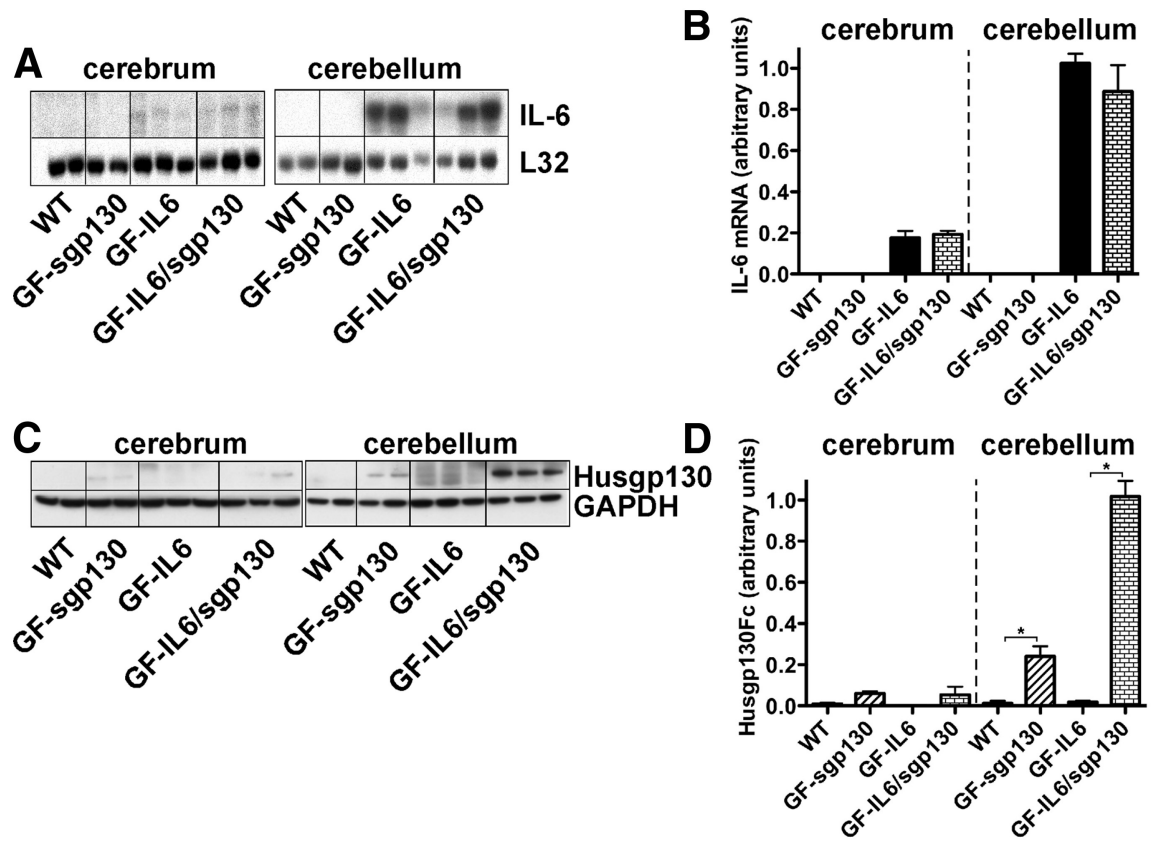

Figure 2. Transgene-encoded IL-6 mRNA and human sgp 130 in the brain of GFAP-IL6 and GFAP-IL6/sgp 130 mice. A, Total RNA was extracted from the brain of 1.5 -month-old mice and analyzed ( $5 \mu \mathrm{g}$ per lane) by RPA and visualized by autoradiography. $\boldsymbol{B}$, Quantification of the band densities in A for IL-6 relative to the housekeeping control L32 was performed by densitometry using NIH ImageJ software. Values represent the mean \pm SEM for two experiments with $n=6$ independent samples; ${ }^{*} p \leq 0.05$. C, Tissue lysates (20 $\mu \mathrm{g}$ protein per lane) from brain of 1.5 -month-old mice were subjected to SDS-PAGE followed by immunoblotting. $\boldsymbol{D}$, Quantification of the band densities in C for sgp 130 relative to GAPDH was performed by densitometry using NIH ImageJ software. Values represent the mean \pm SEM for two experiments with $n=4$ or 6 independent samples; ${ }^{*} p \leq 0.05$.

Tri-Reagent (Sigma-Aldrich) performed according to the manufacturer's instructions. The RNA concentration of the samples was determined by UV spectroscopy at $260 \mathrm{~nm}$.

Ribonuclease protection assays. The construction and characterization of the multiprobe sets for IL-6-responsive genes SOCS3 (Maier et al., 2002), Serpina3n, and IL-6 (Chiang et al., 1994) were described previously. For all probe sets, a fragment of the $L 32$ gene was included and served as an internal loading control. The ribonuclease protection assays (RPAs) were performed and analyzed as described previously (Stalder et al., 1999).

Immunohistochemistry and histochemistry. For the in vivo cell proliferation experiments after BrdU-injection (see above), mice were anesthetized with xylazine/ketamine and subject to transcardial perfusion with cold $4 \%$ paraformaldehyde in PBS for 10 min. Brain, spleen, liver, and a fragment of gut were resected and postfixed in the same fixative for $4 \mathrm{~h}$, and then rinsed with phosphate buffer $0.1 \mathrm{M}$ and placed in 30\% sucrose solution for $48 \mathrm{~h}$. Following sucrose equilibration tissues were frozen with 2-methylbutane on dry ice and stored at $-80^{\circ} \mathrm{C}$ pending the preparation of frozen sections $(30 \mu \mathrm{m})$ using a cryomicrotome (Leica). Sections were then placed in Olmos anti-freezing solution (20\% sucrose, $1 \%$ polyvinylpyrroline, $30 \%$ ethylene glycol in $0.2 \mathrm{M}$ phosphate buffer) and stored at $-20^{\circ} \mathrm{C}$.

For immunohistochemistry (IHC) and histochemistry $(\mathrm{HC})$, free-floating cryosections

(50\% slurry in PBS, GE Healthcare) overnight under continuous rolling at $4^{\circ} \mathrm{C}$. The next day the mixture was centrifuged $\left(5 \mathrm{~min}, 16,000 \times \mathrm{g}, 4^{\circ} \mathrm{C}\right)$ and the protein A Sepharose pellet was washed three times in $10 \mathrm{~mm}$ Tris-HCl, pH 7.5, $150 \mathrm{~mm} \mathrm{NaCl}, 0.2 \%$ NP-40, 2 mm EDTA and twice with $10 \mathrm{~mm}$ Tris- $\mathrm{HCl}, \mathrm{pH}$ 7.5, $500 \mathrm{~mm} \mathrm{NaCl}, 0.2 \% \mathrm{NP}-40,2$ mм EDTA. After the last centrifugation step, the protein A Sepharose pellet was heated at $95^{\circ} \mathrm{C}$ in $50 \mu \mathrm{l}$ of $4 \times \mathrm{SDS}$ gel loading buffer for $5 \mathrm{~min}$. After SDS-PAGE and transfer to membranes, precipitated sgp130-Fc was detected using a monoclonal antibody against human gp130 (B-P4, Diaclone). For standard,10 ng of recombinant sgp130-Fc (Jostock et al., 2001) was used. For detection of sgp130-Fc and coimmunoprecipitation of Hyper-IL-6 with sgp130-Fc from transgenic mouse brain homogenates, $40 \mu \mathrm{l}$ of brain homogenate was incubated with $100 \mu$ l protein A Sepharose (50\% slurry in PBS, GE Healthcare) at $4^{\circ} \mathrm{C}$. After centrifugation $(5 \mathrm{~min}, 16,000 \times g$, $4^{\circ} \mathrm{C}$ ) the pellet was washed three times with $10 \mathrm{~mm}$ Tris- $\mathrm{HCl}, \mathrm{pH} 7.5,150$ $\mathrm{mm} \mathrm{NaCl}, 0.2 \%$ NP-40, 2 mm EDTA and twice with $10 \mathrm{~mm}$ Tris- $\mathrm{HCl}, \mathrm{pH}$ 7.5, $500 \mathrm{~mm} \mathrm{NaCl}, 0.2 \% \mathrm{NP}-40,2$ mм EDTA. After SDS-PAGE and transfer to membranes, the sgp130-Fc was detected using monoclonal antibody against human gp130 (B-P4, Diaclone). Coprecipitated hyperIL-6 was detected with a monoclonal antibody against the human IL-6 receptor (clone 14-18; Chalaris et al., 2007).

For all remaining immunoblot experiments, brain was removed and immediately homogenized in lysis buffer (50 mu Tris- $\mathrm{HCl}, \mathrm{pH} 7.5,1.5 \%$ NP-40, 1 mM EDTA, 10\% v/v glycerol, 1 mm DTT) freshly supplemented with protease and phosphatase inhibitor cocktails (Calbiochem) and manually homogenized using a Wheaton homogenizer. The protein concentration of the samples was quantified using Bradford Assay Reagent (Bio-Rad). Protein lysates $(50 \mu \mathrm{g})$ were resolved by SDS-PAGE transferred to a PVDF membrane (Hybond-P, GE Healthcare) and immunoblot analysis performed as described previously (Wang et al., 2002). Membranes were then probed with monoclonal antibody reactive with human gp130 (clone 29104; R\&D Systems), phospho-STAT3 (Tyr 705), and STAT3 (Cell Signaling Technology) and GAPDH (Millipore).

$R N A$ isolation. Brain was removed and immediately snap-frozen in liquid nitrogen. Total RNA was extracted from the tissue samples using were washed, endogenous peroxidase inhibited by $10 \mathrm{~min}$ incubation in $70 \%$ methanol plus $2 \%$ hydrogen peroxide, washed, and preincubated with blocking buffer (BB; $10 \%$ fetal bovine serum and $0.3 \%$ bovine serum albumin in Tris-buffered saline with $0.1 \%$ Triton (TBST) for $1 \mathrm{~h}$ at room temperature (RT) followed by incubation with rabbit anti-GFAP antibody (Abcam Inc) at 1:2000 dilution in BB overnight at $4^{\circ} \mathrm{C}$ followed by $1 \mathrm{~h}$ at RT. After washing, samples were incubated with a biotinylated anti-rabbit IgG secondary antibody (Vector Laboratories) at 1:500 dilution in BB for $1 \mathrm{~h}$ at RT, washed again and incubated with streptavidinperoxidase (Vector Laboratories) at 1:500 in BB for $1 \mathrm{~h}$ at RT. For visualization of GFAP IHC, sections were incubated with DAB solution for $3 \mathrm{~min}$ according to the manufacturer's directions (Vector Laboratories). Following washing, the sections were dehydrated and mounted onto slides with Eukitt mounting media (Sigma-Aldrich). For BrdU/ doublecortin (DCX) double staining, a similar IHC protocol was used, with incubation with doublecortin antibody (Abcam), at 1:8000 in BB and DAB incubation, but followed by BrdU IHC. The latter included an initial DNA denaturation step, with the sections being treated with $1 \mathrm{~N}$ $\mathrm{HCl}$ for $10 \mathrm{~min}$ on ice followed by $30 \mathrm{~min}$ in $2 \mathrm{~N} \mathrm{HCl}$ at $37^{\circ} \mathrm{C}$, and finally with $0.1 \mathrm{~m}$ borate buffer, $\mathrm{pH} 8.5$, for $12 \mathrm{~min}$ at RT to neutralize the $\mathrm{HCl}$. After washing, sections were incubated with rat anti-BrdU antibody (AbD Serotec) at 1:800 in BB overnight at $4^{\circ} \mathrm{C}$ followed by $1 \mathrm{~h}$ at RT and, after washing, incubated with a biotinylated anti-rat IgG secondary antibody (Vector Laboratories) at 1:500 in BB for $1 \mathrm{~h}$ at RT. After incubation with streptavidin-peroxidase, the sections were developed using nickel-DAB following the manufacturer's directions (Vector Laboratories), and mounted onto slides, as above. For lectin $\mathrm{HC}$ a similar protocol was followed but without BB; samples were incubated with biotinlabeled tomato lectin $\left(1: 150\right.$ in TBST) overnight at $4^{\circ} \mathrm{C}$ followed by $1 \mathrm{~h}$ at RT, and visualized as above. After mounting onto slides, these lectin samples were counterstained with Nissl staining.

In the other experiments where indicated below, hemibrains were removed and fixed in ice-cold 4\% paraformaldehyde in PBS, pH 7.4, overnight at $4^{\circ} \mathrm{C}$, and embedded in paraffin. Paraffin-embedded sag- 
ittal sections ( $5 \mu \mathrm{m})$ were deparaffinized and progressively rehydrated. For laminin IHC, the slides were initially blocked by incubation in 5\% goat serum in TBST followed by incubation overnight at $4^{\circ} \mathrm{C}$ with rabbit antilaminin antibody (Sigma-Aldrich). After washing, samples were incubated with a biotinylated anti-rabbit IgG secondary antibody (Vector Laboratories) for $2 \mathrm{~h}$ at room temperature then washed thoroughly before further incubation for 30 min with $\mathrm{ABC}$ reagent from a Vectastain Elite ABC kit (Vector Laboratories). Sections were developed using DAB plus nickel (Vector Laboratories) as substrate. For phospho-STAT3 cellular localization, antigen retrieval was performed. Slides were brought to boil in $1 \mathrm{~mm}$ EDTA, $\mathrm{pH} 8.0$, and immediately allowed to incubate for $15 \mathrm{~min}$ at $95^{\circ} \mathrm{C}$ and washed in PBS. For staining, the slides were initially blocked by incubation in $5 \%$ goat serum in TBST followed by incubation overnight at $4^{\circ} \mathrm{C}$ with rabbit phospho-STAT3 (Tyr705) monoclonal antibody (Cell Signaling Technology) at a 1:100 dilution. Some sections were incubated with the primary antibody previously blocked with the corresponding blocking peptide according to the manufacturer's instructions and were used as a specificity control for the phospho-STAT3 (Tyr705) antibody. After incubation, sections were washed with TBST and incubated with biotinylated secondary antibody in blocking solution for $30 \mathrm{~min}$. After washing, slides were further incubated for 30 min with $\mathrm{ABC}$ reagent. Secondary antibody and $\mathrm{ABC}$ reagent were from a Vectastain Elite ABC kit (Vector Laboratories). Sections were developed using DAB plus nickel (Vector Laboratories) as substrate. Before second antigen staining, an avidin-biotin blocking step was performed. Second antigen staining was performed to detect the cellular localization of phosphoSTAT3. Biotinylated lectin from Lycopersicon esculentum (Sigma-Aldrich) was used to stain microglia and vascular endothelium, whereas mouse anti-GFAP (Sigma-Aldrich) monoclonal antibodies were used for astrocyte staining. Biotinylated lectin was visualized using a Vectastain Elite ABC kit (Vector Laboratories) used according to the manufacturer's directions. The mouse monoclonal antibodies were visualized using a MOM immunodetection kit (Vector Laboratories). Nova Red (Vector Laboratories) was used as substrate for second antigen detection.

Histological evaluation. The brain was removed from 1.5- and 3-month-old mice ( $N=3-4$ animals per genotype) and stained sections were examined with a bright field microscope (Nikon Eclipse 90i) and images were acquired using a Nikon Digital camera DXM 1200F and Nikon Act-1 v2.70 software. GFAP and Nissl staining were quantified with analysis software Image (NIH). The number of lectin + (with activated morphology), doublecourtin + , and BrdU+ cells, as well as that of blood vessels, was counted in specific CNS areas in a blinded manner. In all cases, at least three tissue sections per animal were used. For staining quantification, several images (3-5) per section were taken depending on the brain area. Because a double staining for lectin and Nissl was performed, a color deconvolution plugin for ImageJ (www.dentistry.bham.ac.uk/ landinig/software/cdeconv/cdeconv.html) was used with all images to separate lectin (DAB) staining from that of Nissl (Ruifrok and Johnston, 2001).
B
STAT3

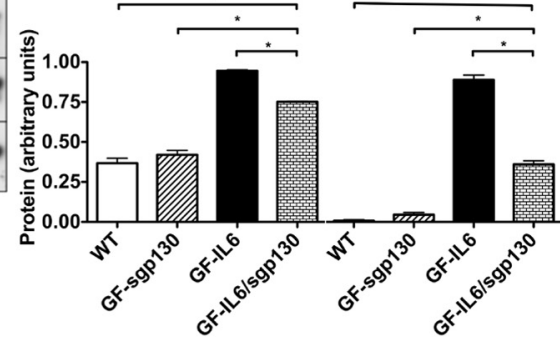

GF-IL6/sgp130

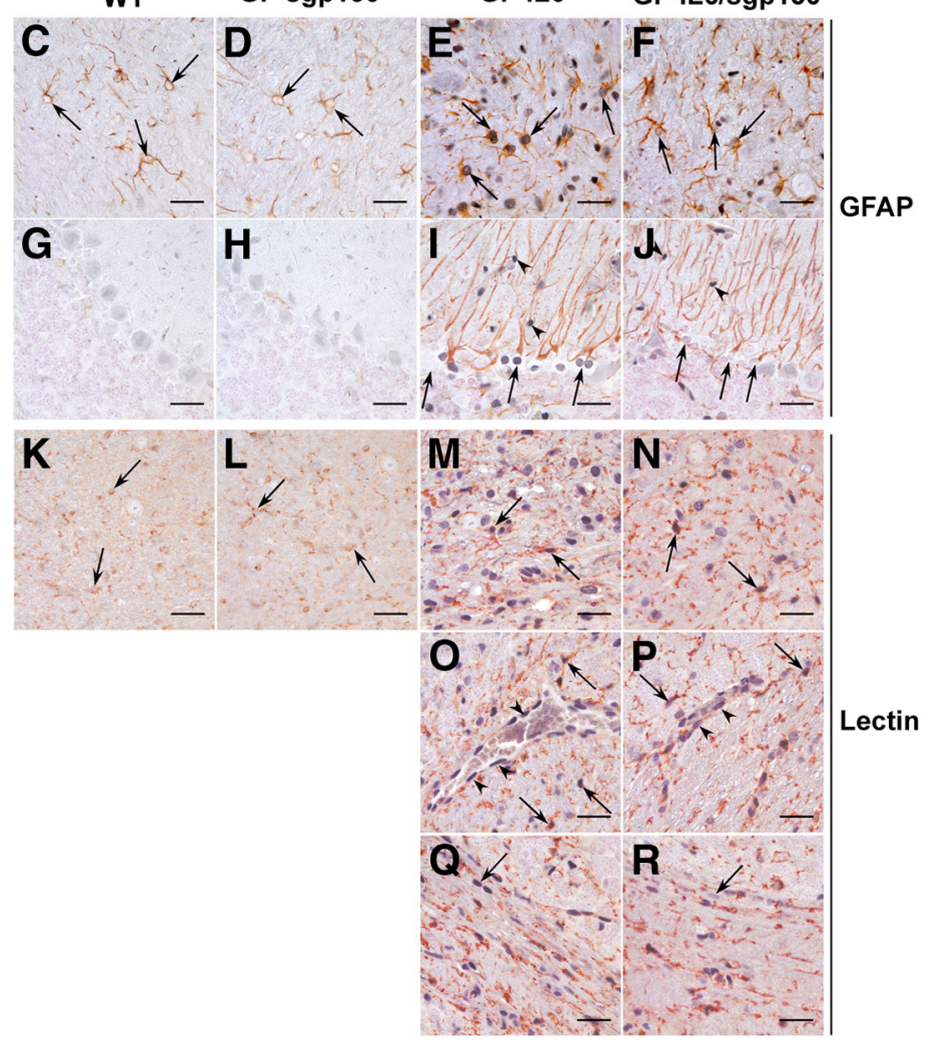

Figure 3. The presence of sgp130 reduces steady-state pY-STAT3 in the cerebellum and in specific cells of the cerebellum of GFAP-IL6 mice. $A$, Tissue lysates (20 $\mu$ g protein per lane) from cerebellum of 1.5-month-old mice were subjected to SDS-PAGE by densitometry using NIH Ima , Q s stware. Values represent the mean + SEM with $n=3$ brains per Paraformaldehyde fixed, paraffin-embedded brain sections $(5 \mu \mathrm{m})$ prepared from 3-month-old mice were processed for immunohistochemistry for pY-STAT3 (purple) and combined with immunohistochemistry for GFAP (red) or histochemistry using tomato lectin binding (red). Scale bar, $25 \mu \mathrm{m}$.

Statistical analysis. Statistical calculations were performed using SPSS statistical software (v17.0 for Windows). Data were analyzed with a Generalized Linear Model (GzLM) with genotype and age as main factors, with sequential Bonferroni adjustment for multiple comparisons in post hoc analysis. $p<0.05$ was considered significant in all analyses. All values are shown as mean $\pm \mathrm{SE}$.

\section{Results}

Production of functional transgene-encoded sgp130-Fc in the brain

The sgp130 protein specifically inhibits IL-6 trans-signaling but not IL-6 classic signaling (Jostock et al., 2001). To generate transgenic mice in which sgp130 was produced in the brain an astrocyte-specific GFAP promoter was used to drive transcription of a minigene designed to encode human sgp130-Fc (Fig. $1 A)$. Following microinjection into the germline of mice a 

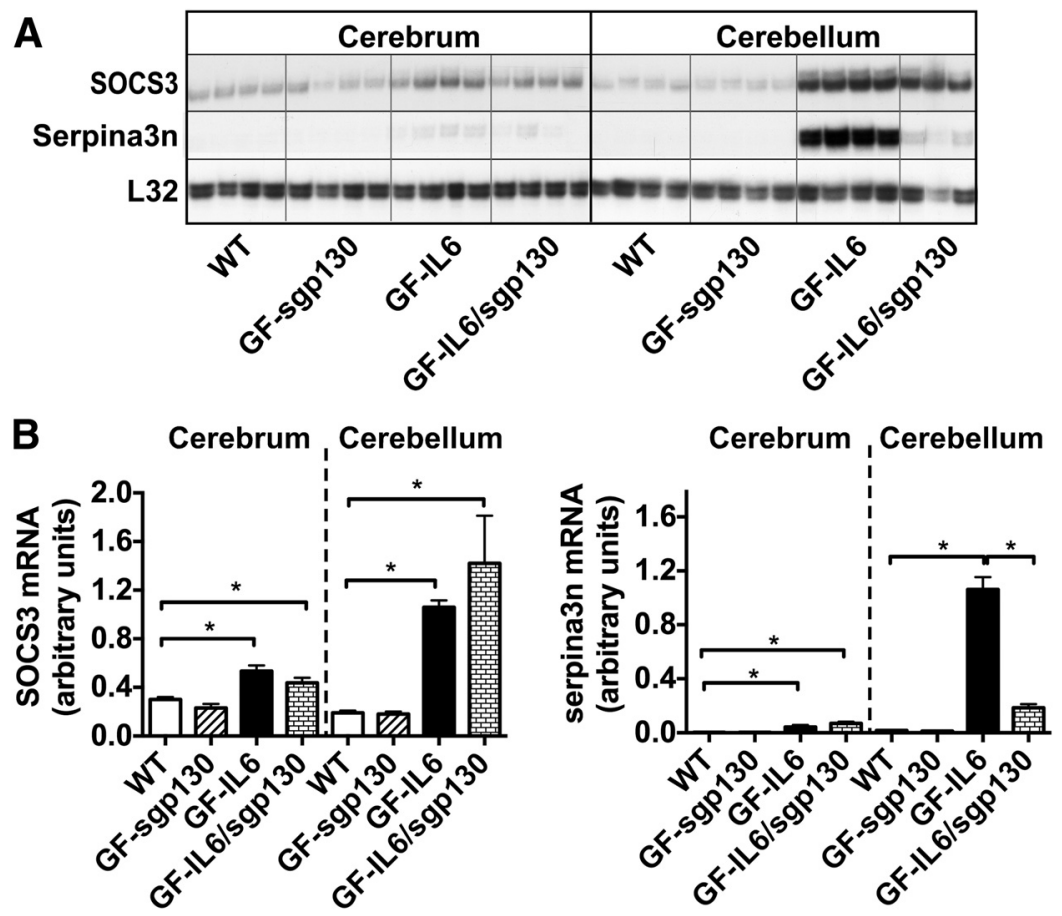

Figure 4. Inhibition of IL-6 trans-signaling resulted in differential expression of the Socs 3 versus Serpina3n genes in the cerebellum of GFAP-IL6 mice. $A$, Total RNA was extracted from the brain of 1.5-month-old mice and analyzed (5 $\mu \mathrm{g}$ per lane) by RPA and visualized by autoradiography. $\boldsymbol{B}$, Quantification of the band densities in $\boldsymbol{A}$ for SOCS3 or Serpina3n relative to the housekeeping control L32 was performed by densitometry using NIH ImageJ software. Values represent the mean \pm SEM with $n=3$ or 4 brains per genotype; ${ }^{*} p \leq 0.05$.

number of transgenic founder offspring were identified and subsequently bred and analyzed for transgene expression. Three lines with the highest expression were further examined for production of the sgp130-Fc in the brain. Immunoblot analysis of brain lysates with an antibody reactive with human sgp130 revealed the presence of sgp130 in the brain of the GFAP-sgp130 mice but not WT littermates (Fig. 1B). We next assessed whether the transgene-encoded sgp130 was secreted from astrocytes. Primary cultures of astrocytes were prepared from the GFAP-sgp130 mice or WT controls and the supernatants and cell lysates analyzed for the presence of sgp130-Fc by immunoblotting. The results showed that sgp130-Fc was detectable in astrocyte-conditioned culture supernatants from GFAP-sgp130 but not WT astrocytes (Fig. 1C). In addition, sgp130 could be immunoprecipitated from culture supernatants of the GFAP-sgp130 astrocytes with protein A Sepharose that binds to the Fc domain. Next we determined whether the transgene-encoded sgp 130-Fc could bind the fusion protein of IL-6 and sIL-6R (hyper-IL-6) when added to brain homogenates. As shown in Figure $1 C$, in brain lysates from GFAPsgp130 but not WT littermates, sIL-6R could be detected by immunoblotting after initial immunoprecipitation with protein A Sepharose. In all, these findings demonstrated that GFAP-sgp130 transgenic mice were generated with production in the brain of functional sgp130 that was capable of binding the IL-6/sIL-6R complex.

\section{Similar transgene-encoded IL-6 mRNA levels in the brain of GFAP-IL6 and GFAP-IL6/sgp130 mice}

The focus of these studies was to generate GFAP-IL6 mice with concomitant astrocyte-targeted production of human sgp $130 \mathrm{Fc}$ in the brain as a means to blocking IL-6 trans-signaling. We therefore next examined the levels of transgene-encoded IL-6 mRNA and sgp130 protein in the brain (Fig. 2). In WT and GFAP-sgp130 mice, IL-6 mRNA was not detectable in either the cerebrum or cerebellum (Fig. 2A,B). As expected IL-6 mRNA was detected in the cerebrum and cerebellum from GFAP-IL6 and GFAPIL6/sgp130 mice, with significantly higher (6-fold) levels of IL-6 mRNA in the cerebellum compared with the cerebrum (Fig. $2 A, B)$. However, there was no significant difference in the IL-6 mRNA levels in either the cerebrum or cerebellum between GFAP-IL6 and GFAP-IL6/sgp130 mice. To investigate the level of transgene-encoded sgp130 production in the brain, Western blot analysis was performed on tissue lysates (Fig. 2C). In neither the cerebrum nor cerebellum from WT or GFAP-IL6 mice was sgp130 protein detectable, although there was an increase in background reactivity in the cerebellum from the GFAP-IL6 mice likely due to the high amounts of Ig present as a result of blood-brain barrier (BBB) breakdown (see Fig. 6C). In contrast to WT and GFAP-IL6 mice, in GFAP-sgp130 and GFAP-IL6/sgp130 mice, Husgp130 protein was detectable in the cerebrum and cerebellum with higher (4-fold) levels present in the cerebellum of GFAP-IL6/ sgp130 mice (Fig. 2D). In conclusion, these results indicated that the level of transgene-encoded IL- 6 production in the brain was comparable between GFAP-IL6 and GFAP-IL6/sgp130 mice. In addition, we confirm the production of Husgp130 protein in the brain from GFAP-sgp130 and GFAP-IL6/sgp130 mice.

\section{pY-STAT3 is reduced in selective cells in the cerebellum of GFAP-IL6/sgp130 mice}

IL-6 signaling is mediated principally through the activation of STAT3 via tyrosine phosphorylation. Initially, the steady-state level of pY-STAT3 was investigated in lysates of cerebellum from the different genotypes. Compared with WT and GFAP-sgp130 controls, in GFAP-IL6 mice a significant increase (95-fold) in the level of pY-STAT3 was observed in the cerebellum (Fig. $3 A, B$ ). However, although pY-STAT3 was also increased in the cerebellum of GFAP-IL6/sgp130 mice, this was significantly lower (2.5fold) than in GFAP-IL6 mice. Therefore, this finding suggested that IL-6-mediated signal transduction is reduced in the GFAPIL6/sgp130 bigenic mice.

To further analyze the cellular basis for the steady-state levels of pY-STAT3 in the brain of GFAP-IL6 and GFAP-IL6/sgp130 mice, we performed dual-label IHC/HC for pY-STAT3 and GFAP (astrocyte marker) or pY-STAT3 and tomato lectin (microglial cell marker). In sections from both WT and GFAP-sgp30 mice there was little or no staining for pY-STAT3 evident throughout the brain in either GFAP (Fig. $3 C, D$, arrows, $G, H$ ) and lectin-bound positive cells (Fig. $3 K, L$, arrows) in the cerebellum. By contrast, significant numbers of cells showed strong nuclear staining for pY-STAT3 in sections from GFAP-IL6 mice. Consistent with our previous finding (Sanz et al., 2008), the majority of these pY-STAT3 cells were GFAP-positive astrocytes (Fig. 3E, arrows), Bergmann glia (Fig. 3I, arrows), lectin-bound 

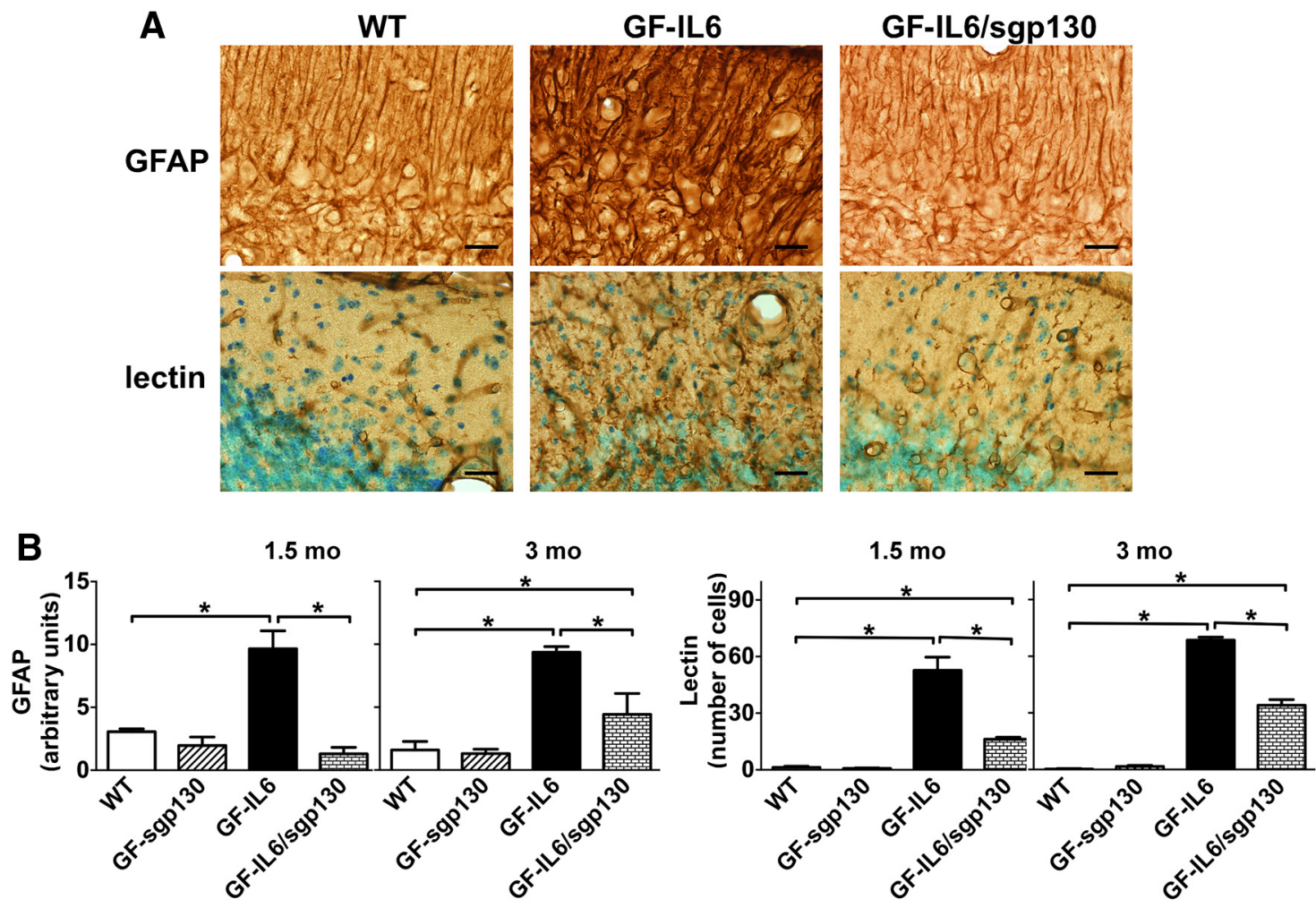

Figure 5. IL-6 trans-signaling contributed to the development of gliosis in the cerebellum of GFAP- $L 6$ mice. A, Paraformaldehyde fixed, free-floating brain sections ( $30 \mu \mathrm{m}$ ) prepared from 1.5-month-old mice were processed for immunohistochemical detection of GFAP or lectin histochemistry. Scale bar, $25 \mu \mathrm{m}$. B, Staining in $\boldsymbol{A}$ and for similarly stained brain sections from 3-month-old mice were quantified with the NIH ImageJ analysis software. These analyses were performed on at least three blinded sections per brain and on a minimum of three brains per genotype. Values represent the mean $\pm S E M ;{ }^{*} p \leq 0.05$.

microglia (Fig. 3M,O, arrows), and vascular endothelial cells (Fig. 3O, arrowheads). However, in sections from GFAP-IL6/ sgp130 mice there was a marked decrease in the number and intensity of pY-STAT3 stained cells compared with GFAP-IL6 mice (Fig. $3 F, N$ ). This decrease could be accounted for in part, by a considerable reduction in pY-STAT3 nuclear staining in astrocytes (Fig. 3F, arrows) and Bergmann glia (Fig. 3J, arrows). In addition, in the cerebellar white matter tracts, nuclei with the morphological characteristics of oligodendrocytes were strongly positive for pY-STAT3 in sections from GFAP-IL6 mice (Fig. 3Q, arrows) but showed only weak staining in GFAP-IL6/sgp130 mice (Fig. 3R, arrows). Similar to GFAP-IL6 mice, in GFAP-IL6/sgp130 mice, lectin-bound microglia (Fig. $3 N, P$, arrows) and vascular endothelial cells (Fig. 3O, arrowheads), were also positive for pY-STAT3. However, the intensity of staining for pY-STAT3 in these cells was more variable compared with GFAP-IL6 mice. In summary, these findings revealed there was a marked decrease in STAT3 activation in selected cell populations within the brain of the GFAP-IL6/sgp130 mice.

\section{Disproportionate alterations in the expression of selected IL-6-responsive genes in the cerebellum of GFAP-IL6/sgp130 mice}

The expression of the IL-6-responsive genes Socs3 (I. Campbell, unpublished observation) and Serpina3n (Campbell et al., 1993) known to be increased markedly in the cerebellum of the GFAPIL6 mice was examined next. The levels of SOCS3 and Serpina3n mRNAs were both increased (5-fold and 55-fold, respectively) significantly in the cerebellum from GFAP-IL6 mice compared with the genotype controls (Fig. 4A,B). In GFAP-IL6/sgp130 mice, SOCS3 mRNA was increased to a similar level as found in
GFAP-IL6 littermates. However, in contrast to SOCS3, in GFAPIL6/sgp130 mice the Serpina3n mRNA was increased only modestly and to significantly lower (6-fold) levels than was observed in GFAP-IL6 mice (Fig. 4A,B). Therefore, these findings indicated that there were disproportionate alterations in the expression of some key IL-6-responsive genes in the cerebellum of the GFAP-IL6/sgp130 mice.

\section{The severity of gliosis is diminished in GFAP-IL6/sgp130 mice}

The development of reactive astrocytosis and microgliosis is particularly pronounced in the cerebellum of the GFAP-IL6 mice (Campbell et al., 1993). We therefore examined the degree of gliosis in the cerebellum of the GFAP-IL6 versus GFAP-IL6/ sgp130 mice by GFAP (astrocyte marker) IHC and lectin HC (microglial marker). As expected, a prominent astrocytosis and microgliosis was observed in the cerebellum of GFAP-IL6 mice (Fig. 5A). Thus, hypertrophied astrocytes with high GFAP staining were readily detected throughout the cerebellum with Bergmann glia also heavily immunostained compared with WT mice. GFAP staining was not altered in GFAP-sgp30 mice compared with WT mice (data not shown), whereas astrogliosis was clearly decreased in GFAP-IL6/sgp130 mice compared with GFAP-IL6 mice. Quantification of GFAP immunostaining performed in 1.5- and 3-month-old mice demonstrated that transgenic expression of sgp130 significantly decreased (7.5-fold and 2-fold, respectively) the astrocytosis of GFAP-IL6 mice at both ages (Fig. $5 B)$. Microglial cells were also activated and appeared to be more numerous in GFAP-IL6 mice, as revealed by both increased lectin staining and morphological changes of these cells, which showed a less ramified structure, retracted processes and with round 
A
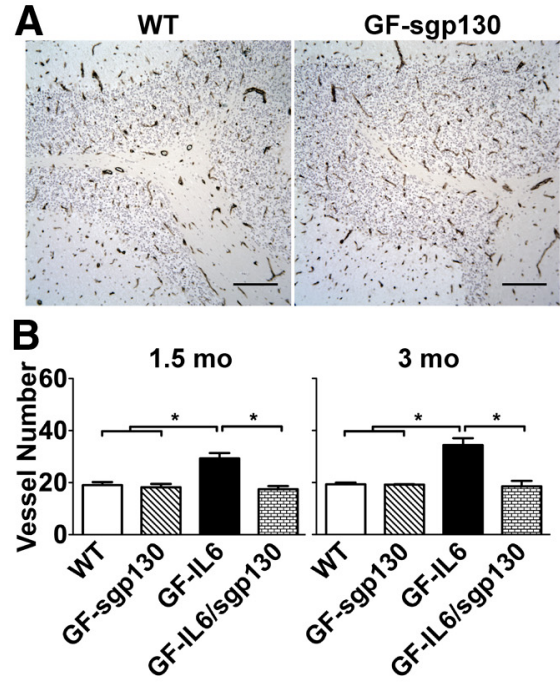

C

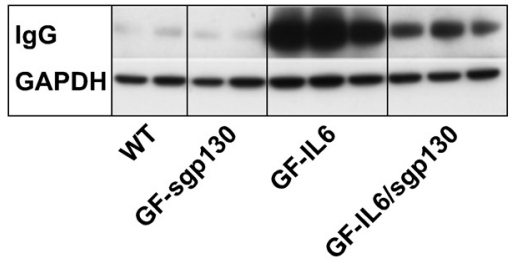

GF-sgp130
GF-IL6
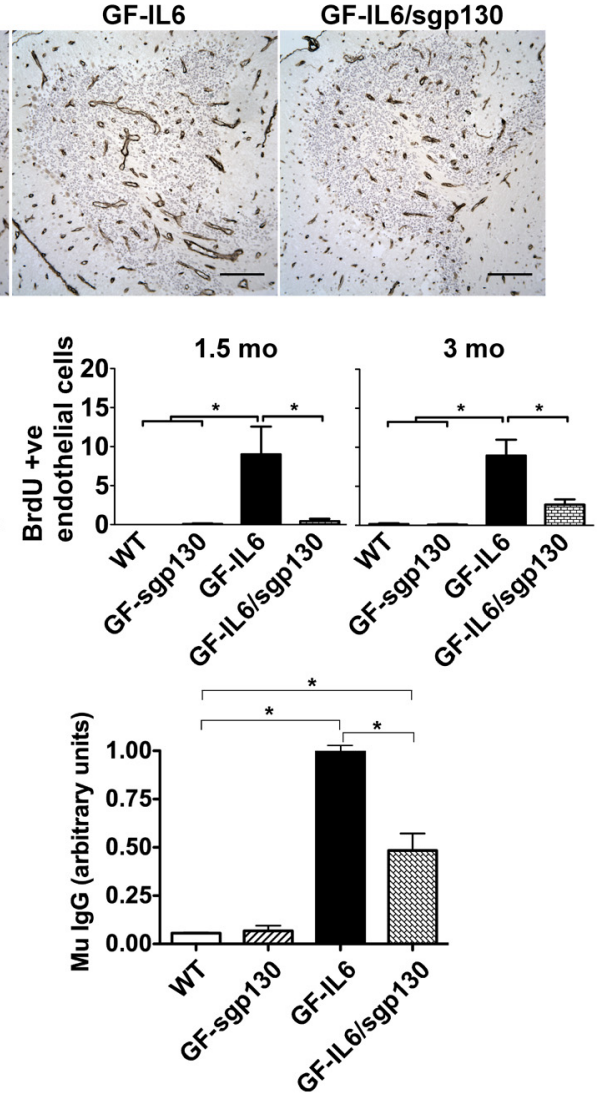

Figure 6. Abnormalities in vascular structure, proliferation and function were reduced significantly in the cerebellum of GFAPIL6 mice by the inhibition of IL- 6 trans-signaling. $\boldsymbol{A}$, Laminin immunohistochemistry was performed on paraformaldehyde fixed, paraffin-embedded sections $(5 \mu \mathrm{m})$ of brain prepared from 3-month-old mice. Scale bar, $50 \mu \mathrm{m}$. B, Vasculogenesis was assessed in free-floating brain sections $(30 \mu \mathrm{m})$ and quantified by direct counting of lectin-stained blood vessels (left) or BrdU-positive endothelial cells (right). This analysis was performed on at least three blinded sections per brain and on a minimum of three brains per genotype. Values represent the mean $\pm S E M ;{ }^{*} p \leq 0.05$. C, The degree of BBB leakage was determined by quantifying the levels of $\mathrm{lgG}$ present in the cerebellum of 3-month-old mice. Tissue lysates ( $20 \mu \mathrm{g}$ protein per lane) were prepared and subject to SDS-PAGE followed by immunoblotting for murine lgG. Quantification of the band densities in C for lgG relative to GAPDH was performed by densitometry using NIH ImageJ software. Values represent the mean \pm SEM with $n=3$ or 4 brains per genotype; ${ }^{*} p \leq 0.05$.

morphology in many cases compared with WT mice (Fig. 5A). However, microgliosis was clearly reduced in GFAP-IL6/sgp 130 mice compared with GFAP-IL6 mice, whereas no effect of sgp130 alone (data not shown) was observable compared with WT mice (Fig. 5). The number of lectin-positive microglial cells with an activated morphology was counted in 1.5- and 3-month-old mice (Fig. $5 B$ ). Consistent with the results above the number of these cells was significantly increased in GFAP-IL6 mice compared with WT mice. However, the number of activated microglial cells was significantly reduced in GFAP-IL6/sgp130 mice compared with GFAP-IL6 mice (Fig. 5B). Whereas no significant difference in the number of activated microglial cells was found for WT versus GF-sgp 130 mice. In contrast to cerebellum, minor changes in lectin staining were observed in cortex and hippocampus (data not shown). In all, these findings indicated that IL-6 transsignaling has a major role in the development of astrogliosis and microgliosis in the GFAP-IL6 mouse.

\section{Reduced vascular alterations and $\mathrm{BBB}$ leakage in GFAP-IL6/sgp130 mice}

Vasculopathy with BBB leakage and angiogenesis principally affecting the cerebellum, have been described previously in the
GFAP-IL6 mice (Campbell et al., 1993; Brett et al., 1995). Here we examined the overall morphology of the blood vessels in the brain using laminin IHC. Compared with WT and sgp130 control littermates, in cerebellum from GFAP-IL6 mice there was increased laminin deposition and associated marked dilation of the blood vessels (Fig. 6A). These vascular changes observed in the GFAP-IL6 cerebellum were reduced noticeably in cerebellum from the GFAP-IL6/sgp130 animals. The number of blood vessels was also quantified in lectin-stained cerebellar sections in 1.5- and 3 month-old mice and showed there was a significant increase (1.5-fold and 1.8 -fold, respectively) in the cerebellum of GFAP-IL6 but not GFAP-IL6/ sgp130 mice (Fig. 6B, left). Consistent with the change in the number of blood vessels, angiogenesis as evaluated with endothelial cell BrdU labeling was increased (22.5- and 3-fold at 1.5- and 3-monthold, respectively) significantly in cerebellum of GFAP-IL6 mice but not in GFAPIL6/sgp130 mice compared with the control genotypes (Fig. $6 \mathrm{~B}$, right). These findings indicated that there is a marked decrease in overall vascular disturbance and in angiogenesis in the cerebellum of the GFAP-IL6/sgp130 mice compared with GFAP-IL6 mice.

To assess the degree of BBB leakage, we performed Western blot analysis for murine IgG on lysates of cerebellum prepared from mice that had been extensively perfused with PBS. The results in Figure 5C showed that there was a significant increase in IgG present in lysates prepared from cerebellum of the GFAP-IL6 mice compared with WT and GFAP-sgp130 mice. Although significantly higher (6-fold) than in WT and GFAP-sgp130 mice, the level of IgG present in lysates of cerebellum from the GFAP-IL6/sgp130 mice was significantly lower (2fold) than in the corresponding GFAP-IL6 mice. In summary, these findings indicated there is a significant reduction in $\mathrm{BBB}$ leakage in the cerebellum of the GFAP-IL6/sgp130 mice.

\section{Hippocampal neurogenesis is rescued in GFAP-IL6/sgp130 mice}

It is known that hippocampal neurogenesis is markedly impaired in GFAP-IL6 mice (Vallières et al., 2002). To assess whether this impaired neurogenesis was influenced by IL-6 trans-signaling, DCX-positive neurons were examined by IHC in the dentate gyrus of the hippocampus (Fig. 7). In accordance with the previous report (Vallières et al., 2002), compared with WT controls, the number of DCX-positive cells was significantly lower (2-fold) in GFAP-IL6 mice at 1.5- and 3-month-old (Fig. 7A,B). However, a significant age-dependent rescuing effect was observed in GFAP-IL6/sgp130 mice in which the number of DCX-positive cells were similar to WT at 1.5 months of age but had diminished significantly by 3 months of age (Fig. $7 A, B$ ). These findings were further verified by the examination of BrdU labeled DCX- 
positive cells. The number of DCX/BrdU double-positive neurons was significantly lower (8-fold and 6-fold, respectively) in hippocampus of GFAP-IL6 mice at 1.5and 3-month-old compared with WT controls (Fig. $7 B$ ). In the hippocampus of 1.5-month-old GFAP-IL6/sgp130 animals the number of DCX/BrdU doublepositive neurons was similar to WT and significantly higher than in GFAP-IL6 mice; however, the rescuing effect observed in the GFAP-IL6/sgp130 animals was absent at 3 months of age (Fig. $7 B$ ). Therefore, particularly at the younger age, IL-6 trans-signaling appears to be a predominant mechanism for the impairment of neurogenesis mediated by IL- 6 .

\section{Reduced neurodegeneration in GFAP-IL6/sgp130 mice}

Progressive neurodegeneration develops in the cerebellum of the GFAP-IL6 mice (Campbell et al., 1993; Brett et al., 1995). Therefore, we evaluated whether the blockade of IL- 6 trans-signaling influences this process. Consistent with the previous reports, evidence of neurodegeneration, as reflected by a significant loss (1.5-fold) of Nissl staining, was already present at 1.5 months of age in GFAP-IL6 mice and decreased (2-fold) further by 3 months of age compared with WT litter mates (Fig. 8A). Further examination of the Nissl stained sections revealed gross disruption of the architecture of the molecular and granule cell layers and a loss of cellularity in the cerebellum from 3-month-old GFAP-IL6 mice (Fig. $8 B)$. In contrast to the GFAP-IL6 mice, the cerebellum from 1.5- and 3-month-old GFAP-IL6/sgp130 mice exhibited similar Nissl staining intensity as the WT control animals (Fig. 8B). Furthermore, both the architecture of the molecular and granule cell layers as well as the degree of cellularity appeared to be largely normal in cerebellum from 3-month-old GFAP-IL6/ sgp130 mice. In all these results indicated that IL-6 trans-signaling has a major influence on the development of neurodegenerative disease in the GFAP-IL6 mice.

\section{Discussion}

The use of sgp130 to block IL-6 transsignaling specifically has proven to be a valuable tool for evaluating this process in various biological settings where IL- 6 is implicated (Rose-John et al., 2006). Here the development of a transgenic mouse model with the production of sgp130 targeted to the CNS afforded us the unique opportunity to assess the role of trans-signaling in mediating IL-6 actions in the CNS. The validity of this novel model was illustrated by the demonstration that cultured astrocytes from the ${ }^{*} p \leq 0.05$.
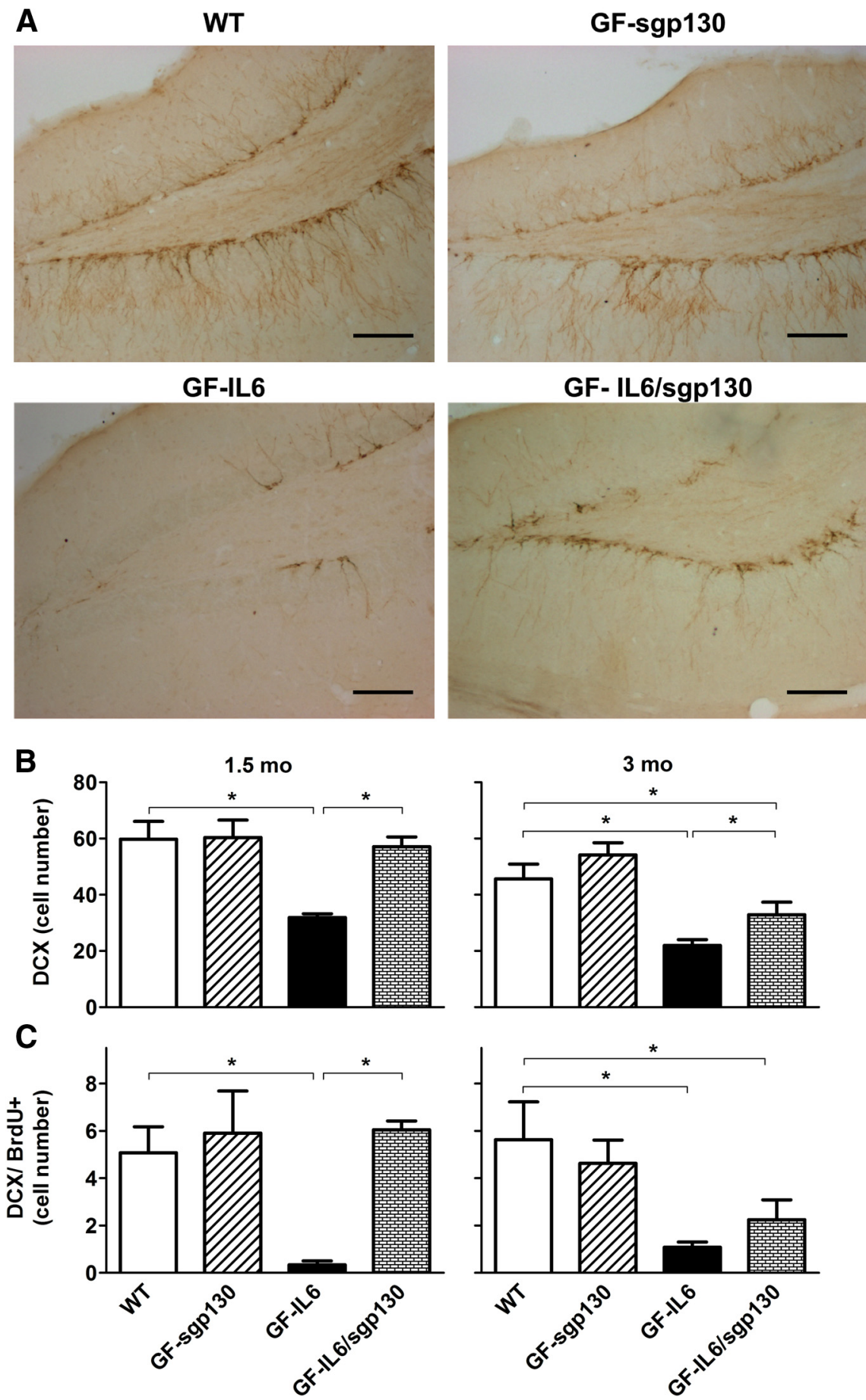

Figure 7. Defective hippocampal neurogenesis was rescued in young GFAP-IL6 mice with IL-6 trans-signaling blockade. $A$, Paraformaldehyde fixed, free-floating brain sections $(30 \mu \mathrm{m})$ prepared from 1.5- or 3-month-old mice that were injected with BrdU, were processed for immunohistochemical detection of $D C X$. Scale bar, $100 \mu \mathrm{m}$. B, Quantification of the data presented in $\boldsymbol{A}$. This analysis was performed on at least three blinded sections per brain and on a minimum of three brains per genotype. Values represent the mean $\pm \mathrm{SEM} ;{ }^{*} p \leq 0.05$. C, A separate set of free-floating brain sections was processed for dual-label immunohistochemical detection of DCX and BrdU and the number of DCX and BrdU double-positive cells counted. This analysis was performed on at least three blinded sections per brain and on a minimum of three brains per genotype. Values represent the mean $\pm S E M$; brain of the GFAP-gp130 mice actively secreted transgeneencoded sgp130. Moreover, consistent with its role in blocking trans-signaling, we showed in lysates of brain from the GFAPsgp130 mice that sgp130 was able to bind sIL-6R/IL-6. Therefore, by intercrossing GFAP-IL6 and GFAP-sgp130 transgenic 
A
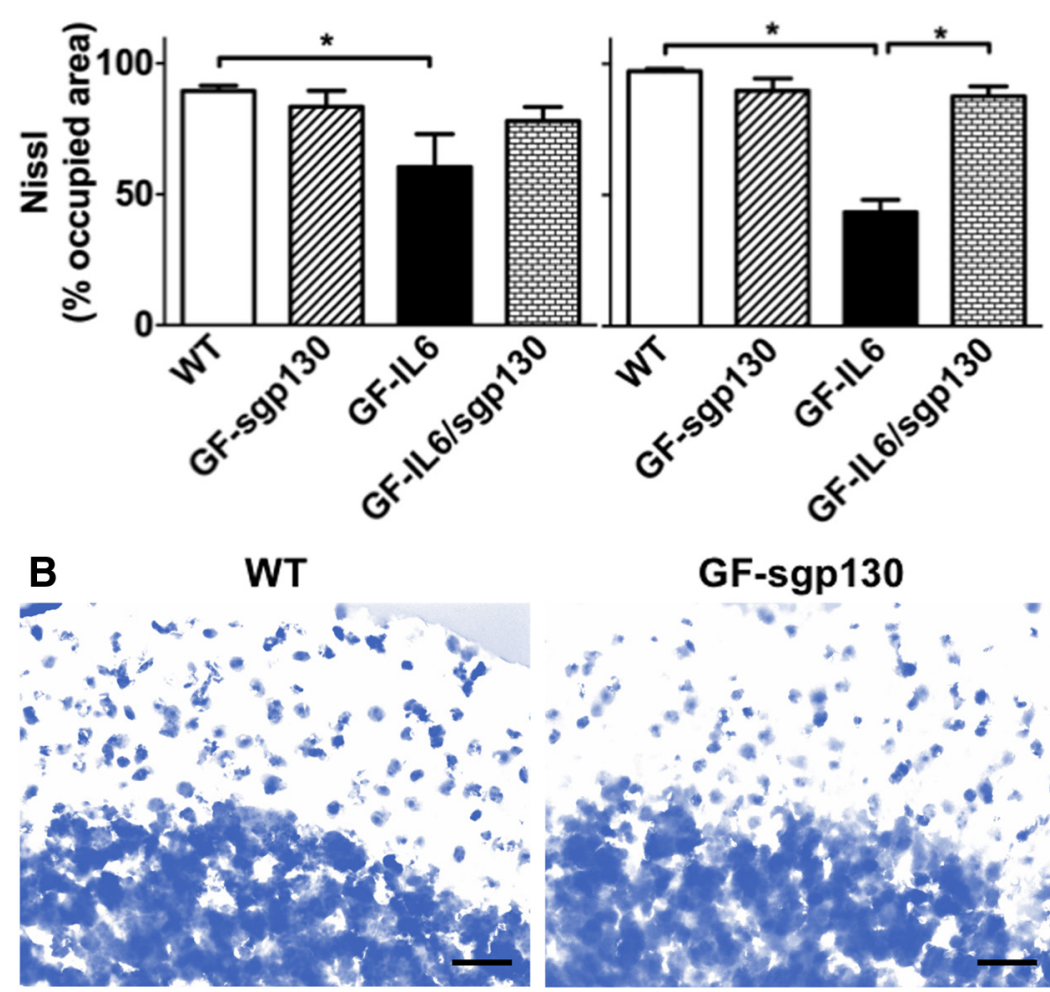

GF-IL6
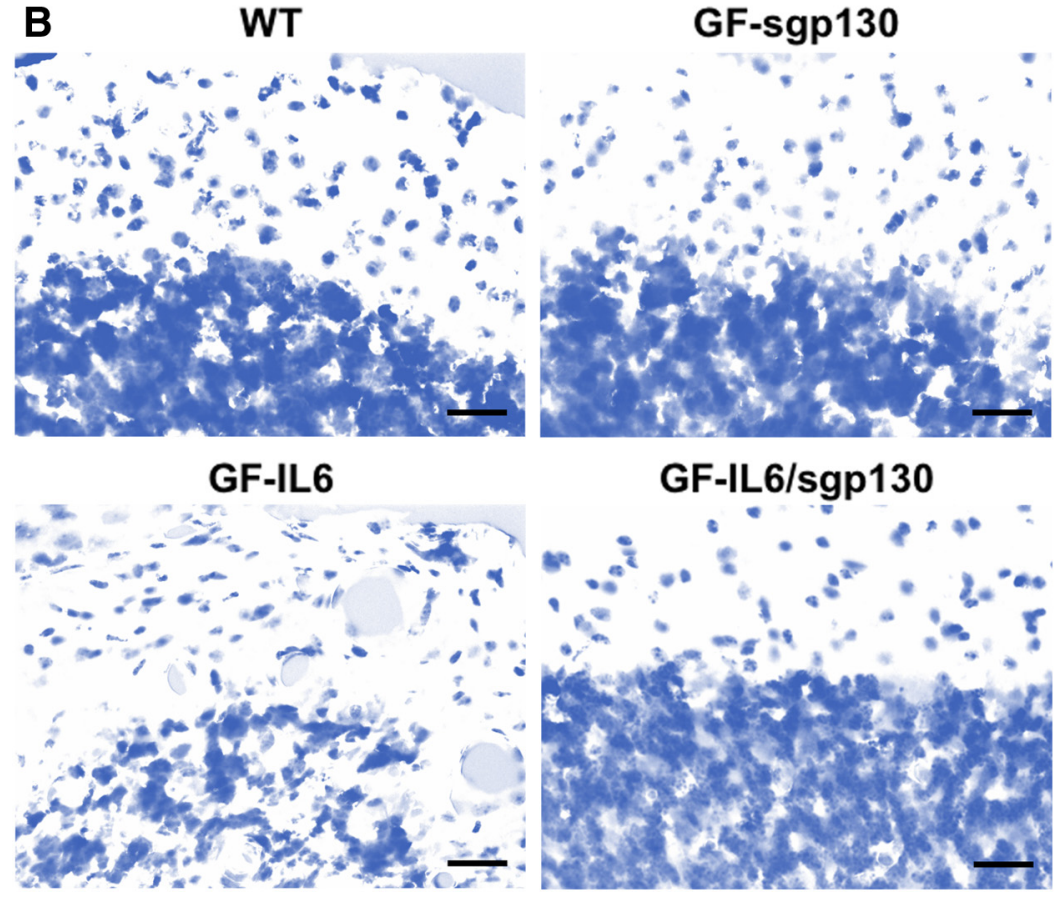

GF-IL6/sgp130

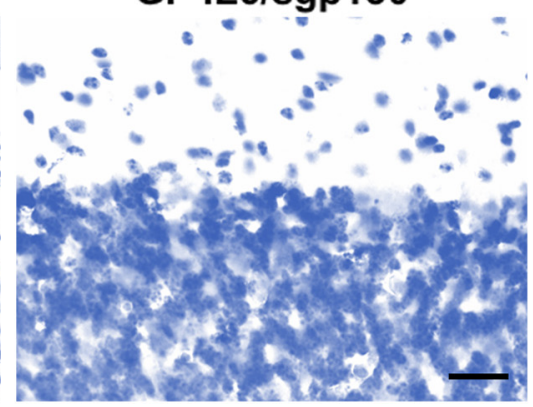

Figure 8. Inhibition of IL-6 trans-signaling prevents neurodegeneration in the cerebellum of GFAP-IL6 mice. $A$, Free-floating brain sections were stained with Nissl and quantified with the NIH ImageJ analysis software. This analysis was performed on at least three blinded sections per brain and on a minimum of three brains per genotype. Values represent the mean \pm SD; ${ }^{*} p \leq$ 0.05. $\boldsymbol{B}$, Nissl stained free-floating brain sections $(30 \mu \mathrm{m})$ from 3-month-old mice. Note loss of architecture of the granule and molecular cell layers, as well as loss of cellularity in GFAP-IL6 cerebellum compared with an age-matched GFAP-IL6/sgp 130 littermate. Scale bar, $25 \mu \mathrm{m}$.

mice we were able to generate bigenic mice with coproduction of IL-6 and sgp130 in the brain. Despite similar levels of IL-6 gene expression in the CNS, in comparison with GFAP-IL6 mice, the GFAP-IL6/sgp130 mice had a marked reduction in gp130-coupled signal pathway activation which was paralleled by an attenuation of a number of hallmark neuropathologic alterations characteristic of the GFAP-IL6 mice, including astrogliosis and microgliosis, BBB leakage, vascular proliferation, and neurodegeneration as well as the rescue of impaired neurogenesis. Interestingly, the response of selective cells (e.g., Bergmann glia) or the expression of specific IL-6 target genes (e.g., Serpina3n) known to be regulated by IL-6 transsignaling were disproportionately affected in the brain of the GFAP-IL6/sgp130 mice. Thus, these findings suggest that many key neuropathogenic effects of IL- 6 are mediated by trans-signaling.
Similar to our previous finding (Sanz et al., 2008), immunostaining for pYSTAT3 identified IL-6 responder cells in GFAP-IL6 mice to be predominantly astrocytes, microglia and cerebrovascular endothelial cells. However, in bigenic mice a significant reduction in $\mathrm{pY}$ STAT3 corresponded to markedly lower pY-STAT3 staining in select cells of the cerebellum including astrocytes and Bergmann glia while microglia or cerebrovascular endothelial cells were much less affected. This is consistent with previous in vitro studies that showed the astrocyte response to IL-6 depends on trans-signaling (März et al., 1999; Van Wagoner et al., 1999). The strong astrogliosis seen in the GFAP-IL6 mice (Campbell et al., 1993; Chiang et al., 1994) further highlights the importance of IL-6 in modulating astrocyte function. Other gp130 family members including LIF (Holmberg and Patterson, 2006; Nakanishi et al., 2007) and CNTF (Kahn et al., 1995; Levison et al., 1998) also modulate astroglial responsiveness suggesting common involvement of STAT3 signaling in this process. Moreover, mice with a conditional deletion of STAT3 in astrocytes have reduced astrocyte activation in response to spinal cord injury (Herrmann et al., 2008). The central role of trans-signaling in mediating IL-6 activation of STAT3 in astrocytes highlighted here, likely translates into the reduction in astrogliosis when trans-signaling was blocked by sgp 130 . In further support of this notion, transgenic mice with systemic production of human IL6/sIL-6R but not IL-6 alone exhibited neurologic signs in association with the development of astrogliosis in the CNS (Brunello et al., 2000).

Our studies further illustrate the proinflammatory nature of chronic IL-6 production in the CNS associated with robust microgliosis in the cerebellum of GFAP-IL6 mice. Previously it was shown that the development of neurodegenerative changes and progressive learning deficit in GFAP-IL6 mice correlated with the degree of microgliosis (Heyser et al., 1997). Here we found that the extent of microgliosis was markedly decreased in the cerebellum of the GFAP-IL6/sgp130 mice. Whether this attenuation of the microglial response to IL- 6 in the presence of sgp130 reflected reduced trans-signaling or was due to other factors such as the decreased astrogliosis, vascular disease and neurodegeneration, is unclear. In contrast to astrocytes, rodent microglia have been shown to respond to IL-6 via classic signaling (Lin and Levison, 2009). The attenuation of microgliosis occurred despite evidence for activation of STAT3 in these cells suggesting other factors may be involved in the reduced microglial response rather than reduced IL- 6 trans-signaling. However, it was shown that while cultured microglia can respond to IL-6 
alone with robust STAT3 activation, modulation of certain responses of these cells requires the presence of sIL-6R and is mediated by trans-signaling (Lin and Levison, 2009). This highlights an additional level of complexity in the microglial response to IL-6, which may mount differential responses to IL-6 communicating by classic versus trans-signaling.

The notion that the same cell may respond differentially to classic versus trans-signaling is intriguing and has important implications for our understanding of how IL-6 functions. Our findings suggest such a process might involve the differential responsiveness of specific genes to classic versus trans-signaling. Thus, the serpina3n mRNA was high in the cerebellum of GFAPIL6 mice but was almost absent from cerebellum of GFAP-IL6 mice with trans-signaling blockade. Interestingly, such a differential response was not found for the expression of another IL-6regulated gene, Socs3, which was significantly elevated in both GFAP-IL6 and GFAP-IL6/sgp130 brain. The basis for the lack of induction of the Serpina3n gene in the brain of the GFAP-IL6/ sgp130 mice is unknown. Possible explanations include restricted expression of this gene to cells that can only respond to transsignaling such as astrocytes or that this gene is regulated directly by IL- 6 trans-signaling and not by classic signaling. In support of the latter possibility, it has been shown previously that Serpina3n mRNA is expressed widely in the cerebellum of GFAP-IL6 mice (Chiang et al., 1994). Furthermore, we have shown that whereas the expression of the Socs 3 gene is induced by both classic signaling and trans-signaling in murine cultured microglia, expression of the Serpina $3 n$ gene is stimulated by IL- 6 trans-signaling only (R. Frausto and I. Campbell, unpublished observation). Surprisingly, the level of Socs3 gene expression was unaltered by transsignaling blockade in the GFAP-IL6 mice. Possible explanations for this observation include, (1) that the signal threshold required for activation of Socs 3 gene expression may be very low, (2) the expression of this gene may be restricted to cells in the brain such as microglia that respond to IL-6 via classic signaling, and (3) that factors other than IL-6 may regulate the expression of the Socs 3 gene in this pathological setting-the expression of the Socs 3 gene is stimulated by a wide range of other cytokines and growth factors (Auernhammer et al., 1999; Cassatella et al., 1999).

The cerebrovascular endothelium is highly responsive to IL-6 production in the CNS as evidenced by a variety of physical, molecular and functional changes observed in this tissue in the cerebellum of GFAP-IL6 mice (Campbell et al., 1993; Brett et al., 1995). Despite the evidence here and from previous studies that human (Yao et al., 2006) and murine (Fee et al., 2000) cerebrovascular endothelial cells can respond to IL-6 via classic signaling we observed a significant reduction in vascular alterations in the cerebellum of GFAP-IL6/sgp130 mice. Despite the clear evidence that STAT3 activation was relatively unperturbed in these mice, we found that vascular proliferation was significantly reduced suggesting that the response of these cells to IL-6 was not overtly impacted by the blocking of trans-signaling. One outcome of chronic angiogenesis in the cerebellum of the GFAP-IL6 mice is the permanent loss of BBB integrity and consequent increased leakage of the blood vessels (Brett et al., 1995). Consistent with our findings here, the significant reduction in vascular endothelial cell proliferation in the cerebellum of the GFAP-IL6/sgp130 mice was accompanied by a marked decrease in BBB leakage.

A spectrum of molecular and cellular changes in the GFAPIL6 mice contribute to progressive neurodegeneration with significant loss of neuronal integrity and function (Campbell et al., 1993; Brett et al., 1995). The neurodegenerative phenotype of the GFAP-IL6 mice is likely compounded further by a marked reduc- tion in neurogenesis (Vallières et al., 2002). The paucity of STAT3 activation in neurons in the CNS of the GFAP-IL6 mice indicates that these cells are relatively unresponsive to chronic IL- 6 production and suggests that the neurodegeneration in these mice may be mediated by a neurotoxic environment generated by other factors such as the microgliosis and the leaky BBB. The significant reduction in the severity of cerebellar neurodegeneration observed in the GFAP-IL6/sgp130 mice may reflect the overall decrease in these pathologic changes including reduced gliosis and BBB leakage. In support of this, previous studies established there is a close correlation between the degree of microglial activation and progressive neurodegeneration and learning impairment in the GFAP-IL6 mice (Heyser et al., 1997). Moreover, a central role for inflammation and microglial reactivity has been linked to diminished neurogenesis (Ekdahl et al., 2003; Monje et al., 2003). Interestingly, although there was a complete rescue of neurogenesis in GFAP-IL6/sgp130 mice at 1.5 months of age this was not sustained at the older age examined. Therefore, neurogenesis appears to be particularly sensitive to perturbation by IL-6 and the inflammatory milieu of the GFAP-IL6 brain also reflected by the fact that markedly impaired neurogenesis is found in the hippocampus of these mice a region of the brain with much lower levels of transgene-encoded IL-6 production and pathologic alterations.

In concluding, these data provide a remarkable demonstration of the involvement of trans-signaling in mediating cellular communication by IL- 6 in the CNS. The findings indicate that trans-signaling is crucial for IL-6 responsiveness by selected cellular and molecular targets in the brain including astrocytes and Bergmann glia. Despite this selectivity, blocking of transsignaling had broad ranging benefit, markedly reducing many of the detrimental effects of IL- 6 in the brain. Based on these findings the targeting of IL- 6 trans-signaling may represent a rationale therapeutic approach for the treatment of the numerous neuroinflammatory and neurodegenerative diseases in which this cytokine has been implicated.

\section{References}

Auernhammer CJ, Bousquet C, Melmed S (1999) Autoregulation of pituitary corticotroph SOCS-3 expression: characterization of the murine SOCS-3 promoter. Proc Natl Acad Sci U S A 96:6964-6969. CrossRef Medline

Brett FM, Mizisin AP, Powell HC, Campbell IL (1995) Evolution of neuropathologic abnormalities associated with blood-brain barrier breakdown in transgenic mice expressing interleukin-6 in astrocytes. J Neuropathol Exp Neurol 54:766-775. CrossRef Medline

Brunello AG, Weissenberger J, Kappeler A, Vallan C, Peters M, Rose-John S, Weis J (2000) Astrocytic alterations in interleukin-6/soluble interleukin-6 receptor alpha double-transgenic mice. Am J Pathol 157:1485-1493. CrossRef Medline

Burton MD, Sparkman NL, Johnson RW (2011) Inhibition of interleukin-6 trans-signaling in the brain facilitates recovery from lipopolysaccharideinduced sickness behavior. J Neuroinflammation 8:54. CrossRef Medline

Burton MD, Rytych JL, Freund GG, Johnson RW (2013) Central inhibition of interleukin- 6 trans-signaling during peripheral infection reduced neuroinflammation and sickness in aged mice. Brain Behav Immun 30:6672. CrossRef Medline

Campbell IL (1998) Structural and functional impact of the transgenic expression of cytokines in the CNS. Ann N Y Acad Sci 840:83-96. CrossRef Medline

Campbell IL, Abraham CR, Masliah E, Kemper P, Inglis JD, Oldstone MB, Mucke L (1993) Neurologic disease induced in transgenic mice by the cerebral overexpression of interleukin 6. Proc Natl Acad Sci U S A 90: 10061-10065. CrossRef Medline

Campbell IL, Hofer MJ, Pagenstecher A (2010) Transgenic models for cytokine-induced neurological disease. Biochim Biophys Acta 1802:903917. CrossRef Medline 
Cassatella MA, Gasperini S, Bovolenta C, Calzetti F, Vollebregt M, Scapini P, Marchi M, Suzuki R, Suzuki A, Yoshimura A (1999) Interleukin-10 (IL10) selectively enhanced CIS3/SOCS3 mRNA expression in human neutrophils: evidence for an IL-10-induced pathway that is independent of STAT protein activation. Blood 94:2880-2889. Medline

Chalaris A, Rabe B, Paliga K, Lange H, Laskay T, Fielding CA, Jones SA, Rose-John S, Scheller J (2007) Apoptosis is a natural stimulus of IL6R shedding and contributes to the proinflammatory trans-signaling function of neutrophils. Blood 110:1748-1755. CrossRef Medline

Chiang CS, Stalder A, Samimi A, Campbell IL (1994) Reactive gliosis as a consequence of interleukin- 6 expression in the brain: studies in transgenic mice. Dev Neurosci 16:212-221. CrossRef Medline

Ekdahl CT, Claasen JH, Bonde S, Kokaia Z, Lindvall O (2003) Inflammation is detrimental for neurogenesis in adult brain. Proc Natl Acad Sci U S A 100:13632-13637. CrossRef Medline

Fee D, Grzybicki D, Dobbs M, Ihyer S, Clotfelter J, Macvilay S, Hart MN, Sandor M, Fabry Z (2000) Interleukin 6 promotes vasculogenesis of murine brain microvessel endothelial cells. Cytokine 12:655-665. CrossRef Medline

Heinrich PC, Behrmann I, Haan S, Hermanns HM, Müller-Newen G, Schaper F (2003) Principles of interleukin (IL)-6-type cytokine signalling and its regulation. Biochem J 374:1-20. CrossRef Medline

Herrmann JE, Imura T, Song B, Qi J, Ao Y, Nguyen TK, Korsak RA, Takeda K, Akira S, Sofroniew MV (2008) STAT3 is a critical regulator of astrogliosis and scar formation after spinal cord injury. J Neurosci 28:7231-7243. CrossRef Medline

Heyser CJ, Masliah E, Samimi A, Campbell IL, Gold LH (1997) Progressive decline in avoidance learning paralleled by inflammatory neurodegeneration in transgenic mice expressing interleukin 6 in the brain. Proc Natl Acad Sci U S A 94:1500-1505. CrossRef Medline

Holmberg KH, Patterson PH (2006) Leukemia inhibitory factor is a key regulator of astrocytic, microglial and neuronal responses in a low-dose pilocarpine injury model. Brain Res 1075:26-35. CrossRef Medline

Jostock T, Müllberg J, Ozbek S, Atreya R, Blinn G, Voltz N, Fischer M, Neurath MF, Rose-John S (2001) Soluble gp130 is the natural inhibitor of soluble interleukin-6 receptor transsignaling responses. Eur J Biochem 268:160-167. CrossRef Medline

Kahn MA, Ellison JA, Speight GJ, de Vellis J (1995) CNTF regulation of astrogliosis and the activation of microglia in the developing rat central nervous system. Brain Res 685:55-67. CrossRef Medline

Levison SW, Hudgins SN, Crawford JL (1998) Ciliary neurotrophic factor stimulates nuclear hypertrophy and increases the GFAP content of cultured astrocytes. Brain Res 803:189-193. CrossRef Medline

Lin HW, Levison SW (2009) Context-dependent IL-6 potentiation of interferon-gamma-induced IL- 12 secretion and CD40 expression in murine microglia. J Neurochem 111:808-818. CrossRef Medline

Lust JA, Donovan KA, Kline MP, Greipp PR, Kyle RA, Maihle NJ (1992) Isolation of an mRNA encoding a soluble form of the human interleukin-6 receptor. Cytokine 4:96-100. CrossRef Medline

Mackiewicz A, Schooltink H, Heinrich PC, Rose-John S (1992) Complex of soluble human IL-6-receptor/IL-6 up-regulates expression of acutephase proteins. J Immunol 149:2021-2027. Medline

Maier J, Kincaid C, Pagenstecher A, Campbell IL (2002) Regulation of signal transducer and activator of transcription and suppressor of cytokine signaling gene expression in the brain of mice with astrocyte-targeted production of IL-12 and experimental autoimmune encephalomyelitis. Am J Pathol 160:271-288. CrossRef Medline

März P, Herget T, Lang E, Otten U, Rose-John S (1997a) Activation of gp130 by IL-6/soluble IL-6 receptor induces neuronal differentiation. Eur J Neurosci 9:2765-2773. CrossRef Medline

März P, Heese K, Hock C, Golombowski S, Müller-Spahn F, Rose-John S, Otten U (1997b) Interleukin-6 (IL-6) and soluble forms of IL-6 receptors are not altered in cerebrospinal fluid of Alzheimer's disease patients. Neurosci Lett 239:29-32. CrossRef Medline

März P, Heese K, Dimitriades-Schmutz B, Rose-John S, Otten U (1999) Role of interleukin- 6 and soluble IL-6 receptor in region-specific induc- tion of astrocytic differentiation and neurotrophin expression. Glia 26: 191-200. CrossRef Medline

Michalopoulou M, Nikolaou C, Tavernarakis A, Alexandri NM, Rentzos M, Chatzipanagiotou S, Cambouri C, Vassilopoulos D (2004) Soluble interleukin-6 receptor (sIL-6R) in cerebrospinal fluid of patients with inflammatory and noninflammatory neurological diseases. Immunol Lett 94:183-189. CrossRef Medline

Monje ML, Toda H, Palmer TD (2003) Inflammatory blockade restores adult hippocampal neurogenesis. Science 302:1760-1765. CrossRef Medline

Müllberg J, Schooltink H, Stoyan T, Günther M, Graeve L, Buse G, Mackiewicz A, Heinrich PC, Rose-John S (1993) The soluble interleukin-6 receptor is generated by shedding. Eur J Immunol 23:473-480. CrossRef Medline

Müllberg J, Vollmer P, Althoff K, März P, Rose-John S (1999) Generation and function of the soluble interleukin- 6 receptor. Biochem Soc Trans 27:211-219. Medline

Nakanishi M, Niidome T, Matsuda S, Akaike A, Kihara T, Sugimoto H (2007) Microglia-derived interleukin-6 and leukaemia inhibitory factor promote astrocytic differentiation of neural stem/progenitor cells. Eur J Neurosci 25:649-658. CrossRef Medline

Narazaki M, Yasukawa K, Saito T, Ohsugi Y, Fukui H, Koishihara Y, Yancopoulos GD, Taga T, Kishimoto T (1993) Soluble forms of the interleukin-6 signal-transducing receptor component gp130 in human serum possessing a potential to inhibit signals through membraneanchored gp130. Blood 82:1120-1126. Medline

Rabe B, Chalaris A, May U, Waetzig GH, Seegert D, Williams AS, Jones SA, Rose-John S, Scheller J (2008) Transgenic blockade of interleukin 6 transsignaling abrogates inflammation. Blood 111:1021-1028. CrossRef Medline

Röhl C, Sievers J (2005) Microglia is activated by astrocytes in trimethyltin intoxication. Toxicol Appl Pharmacol 204:36-45. CrossRef Medline

Rose-John S, Heinrich PC (1994) Soluble receptors for cytokines and growth factors: generation and biological function. Biochem J 300:281290. Medline

Rose-John S, Scheller J, Elson G, Jones SA (2006) Interleukin-6 biology is coordinated by membrane-bound and soluble receptors: role in inflammation and cancer. J Leukoc Biol 80:227-236. CrossRef Medline

Ruifrok AC, Johnston DA (2001) Quantification of histochemical staining by color deconvolution. Anal Quant Cytol Histol 23:291-299. Medline

Sanz E, Hofer MJ, Unzeta M, Campbell IL (2008) Minimal role for STAT1 in interleukin-6 signaling and actions in the murine brain. Glia 56:190 199. CrossRef Medline

Scheller J, Chalaris A, Schmidt-Arras D, Rose-John S (2011) The pro- and anti-inflammatory properties of the cytokine interleukin-6. Biochim Biophys Acta 1813:878-888. CrossRef Medline

Spooren A, Kolmus K, Laureys G, Clinckers R, De Keyser J, Haegeman G, Gerlo S (2011) Interleukin-6, a mental cytokine. Brain Res Rev 67:157183. CrossRef Medline

Stalder A, Pagenstecher A, Kincaid C, Campbell IL (1999) Analysis of gene expression by multiprobe RNase protection assay. In: Neurodegeneration methods and protocols. (Harry J, Tilson HA, eds), pp 53-66. Totowa, NJ: Human.

Vallières L, Campbell IL, Gage FH, Sawchenko PE (2002) Reduced hippocampal neurogenesis in adult transgenic mice with chronic astrocytic production of interleukin-6. J Neurosci 22:486-492. Medline

Van Wagoner NJ, Oh JW, Repovic P, Benveniste EN (1999) Interleukin-6 (IL-6) production by astrocytes: autocrine regulation by IL- 6 and the soluble IL-6 receptor. J Neurosci 19:5236-5244. Medline

Wang J, Schreiber RD, Campbell IL (2002) STAT1 deficiency unexpectedly and markedly exacerbates the pathophysiological actions of IFN- $\alpha$ in the central nervous system. Proc Natl Acad Sci U S A 99:16209-16214. CrossRef Medline

Yao JS, Zhai W, Young WL, Yang GY (2006) Interleukin-6 triggers human cerebral endothelial cells proliferation and migration: the role for KDR and MMP-9. Biochem Biophys Res Commun 342:1396-1404. CrossRef Medline 